Article

\title{
The Effect of Different Atomic Substitution at Mn Site on Magnetocaloric Effect in Ni50Mn35Co2Sn13 Alloy
}

\author{
Chengfen Xing ${ }^{1}$, Hu Zhang ${ }^{1, *}$, Kewen Long ${ }^{2,3}$, Yaning Xiao ${ }^{1}$, Hanning Zhang ${ }^{1}$, Zhijie Qiu ${ }^{1}$, \\ Dai He ${ }^{1}$, Xingyu Liu ${ }^{1}$, Yingli Zhang ${ }^{4}$ and Yi Long ${ }^{1}$ \\ 1 School of Materials Science and Engineering, University of Science and Technology of Beijing, Beijing 100083, \\ China; xcf930127@163.com (C.X.); 18811319662@163.com (Y.X.); 13194257375@163.com (H.Z.); \\ qiuzhijiedongdong@163.com (Z.Q.); 18612667069@163.com (D.H.); emptinessooo@163.com (X.L.); \\ longy@mater.ustb.edu.cn (Y.L.) \\ 2 ChuanDong Magnetic Electronic Co., Ltd., FoShan 528513, GuangDong, China; longkewen@cdm21.com \\ 3 ChengXian Technology Co., Ltd., FoShan 528513, GuangDong, China \\ 4 Voggenreiter Technology (Beijing) Co., Ltd., 3006 Jinao International, No. 19 Madian East Rd., Haidian Dist., \\ Beijing 100088, China; peter@vogg-china.com \\ * Correspondence: zhanghu@ustb.edu.cn; Tel.: +86-10-6233-4807
}

Received: 23 June 2018; Accepted: 15 August 2018; Published: 18 August 2018

\begin{abstract}
The effect of different atomic substitutions at $\mathrm{Mn}$ sites on the magnetic and magnetocaloric properties in $\mathrm{Ni}_{50} \mathrm{Mn}_{35} \mathrm{Co}_{2} \mathrm{Sn}_{13}$ alloy has been studied in detail. The substitution of $\mathrm{Ni}$ or $\mathrm{Co}$ for $\mathrm{Mn}$ atoms might lower the Mn content at $\mathrm{Sn}$ sites, which would reduce the $d$ - $d$ hybridization between $\mathrm{Ni}$ $3 d e_{g}$ states and the $3 d$ states of excess Mn atoms at $\mathrm{Sn}$ sites, thus leading to the decrease of martensitic transformation temperature $T_{M}$ in $\mathrm{Ni}_{51} \mathrm{Mn}_{34} \mathrm{Co}_{2} \mathrm{Sn}_{13}$ and $\mathrm{Ni}_{50} \mathrm{Mn}_{34} \mathrm{Co}_{3} \mathrm{Sn}_{13}$ alloys. On the other hand, the substitution of $\mathrm{Sn}$ for $\mathrm{Mn}$ atoms in $\mathrm{Ni}_{50} \mathrm{Mn}_{34} \mathrm{Co}_{2} \mathrm{Sn}_{14}$ would enhance the $p$ - $d$ covalent hybridization between the main group element $(\mathrm{Sn})$ and the transition metal element ( $\mathrm{Mn}$ or Ni) due to the increase of $S n$ content, thus also reducing the $T_{M}$ by stabilizing the parent phase. Due to the reduction of $T_{M}$, a magnetostructural martensitic transition from FM austenite to weak-magnetic martensite is realized in $\mathrm{Ni}_{51} \mathrm{Mn}_{34} \mathrm{Co}_{2} \mathrm{Sn}_{13}$ and $\mathrm{Ni}_{50} \mathrm{Mn}_{34} \mathrm{Co}_{2} \mathrm{Sn}_{14}$, resulting in a large magnetocaloric effect around room temperature. For a low field change of $3 \mathrm{~T}$, the maximum $\Delta S_{M}$ reaches as high as $30.9 \mathrm{~J} / \mathrm{kg} \mathrm{K}$ for $\mathrm{Ni}_{50} \mathrm{Mn}_{34} \mathrm{Co}_{2} \mathrm{Sn}_{14}$. A linear dependence of $\Delta S_{M}$ upon $\mu_{0} H$ has been found in $\mathrm{Ni}_{50} \mathrm{Mn}_{34} \mathrm{Co}_{2} \mathrm{Sn}_{14}$, and the origin of this linear relationship has been discussed by numerical analysis of Maxwell's relation.
\end{abstract}

Keywords: magnetocaloric effect; heusler alloys; magnetic properties

PACS: 75.30.Sg; 81.30.Kf; 75.50.Cc

\section{Introduction}

Over the past decades, Ni-Mn-Z ( $\mathrm{Z}=\mathrm{Ga}$, In, Sn, and Sb) Heusler alloys have attracted significant attention due to its noteworthy multifunction properties, such as magnetic shape memory effect [1], magnetoresistance [2,3], exchange bias (EB) [4], and magnetocaloric effect (MCE) [5,6]. As one of the typical Ni-Mn-Z Heusler alloys, Ni-Mn-Sn alloy undergoes a martensitic transformation from ferromagnetic (FM) austenite to weak-magnetic martensite, which is accompanied with an abrupt change of magnetization $\Delta M$ [6]. This large $\Delta M$ across martensitic transformation results in a high difference of Zeeman energy $E_{z e e m a n}=\mu_{0} H \Delta M$, which drives a metamagnetic transition from the weak-magnetic martensite to FM austenite, thus leading to a large MCE [5,7]. Therefore, it is desirable to enhance the $\triangle M$ during martensitic transformation in order to obtain a large MCE. 
It has been reported that the stoichiometric $\mathrm{Ni}_{2} \mathrm{MnSn}$ alloy does not exhibit martensitic transformation while some Mn-rich Ni-Mn-Sn alloys show martensitic transformation from FM austenite to weak-magnetic martensite [8-10]. However, the excess $\mathrm{Mn}$ atoms would occupy the vacant Sn sites ( $4 b$ positions), and are coupled antiferromagnetically (AFM) to the surrounding Mn atoms on the regular Mn site (4a positions) [11,12]. This fact suggests that excess Mn would lead to the weakness of $\Delta M$ during the martensitic transformation. The introduction of Co can act as a "FM activator" to induce the Mn moments to align in an FM order and enhance the magnetization of austenite phase, thus causing a larger $\triangle M$ as well as a large MCE [12,13]. Similar results have also been reported in other Heusler alloys [14,15], e.g., the substitution of Co for Ni modifies the magnetic structure of the austenite into FM as the preferred state and reduces the martensitic transformation temperature [15]. Furthermore, the martensitic transformation temperature $\left(T_{M}\right)$ increases by substituting Mn with Co atoms, which is probably attributed to the rule of valence electron concentration [16]. Recently however, some studies have shown that the $T_{M}$ does not increase monotonously by increasing the Co substitution for Mn atoms, suggesting that there is a disagreement of the rule of valence electron concentration [12,17]. The substitution of $\mathrm{Mn}$ by Ni atoms in Ni-Mn-Sn alloys increases the $T_{M}$ remarkably while the MCE still remains nearly constant $[18,19]$. In addition, the substitution of Mn by Sn causes a reduction of $T_{M}$ while the MCE remains nearly unchanged [20,21]. Consequently, different atomic substitutions at Mn sites have different effects on the martensitic transformation and the MCE. Unfortunately, to the best of our knowledge, a systematical study on different atomic substitutions at Mn sites in the Ni-Mn-Co-Sn system is still lacking. In the present work, we systematically study the effect of substituting $\mathrm{Ni}, \mathrm{Co}$, and $\mathrm{Sn}$ for $\mathrm{Mn}$ atoms for the magnetic and magnetocaloric properties in $\mathrm{Ni}_{50} \mathrm{Mn}_{35} \mathrm{Co}_{2} \mathrm{Sn}_{13}$ alloy.

\section{Experimental}

The $\mathrm{Ni}_{50} \mathrm{Mn}_{35} \mathrm{Co}_{2} \mathrm{Sn}_{13}$ (parent alloy), $\mathrm{Ni}_{51} \mathrm{Mn}_{34} \mathrm{Co}_{2} \mathrm{Sn}_{13}$ (Ni for $\mathrm{Mn}$ ), $\mathrm{Ni}_{50} \mathrm{Mn}_{34} \mathrm{Co}_{3} \mathrm{Sn}_{13}$ (Co for $\mathrm{Mn}$ ), and $\mathrm{Ni}_{50} \mathrm{Mn}_{34} \mathrm{Co}_{2} \mathrm{Sn}_{14}$ ( $\mathrm{Sn}$ for $\mathrm{Mn}$ ) alloys were prepared by arc melting appropriate proportion of constituent components with a purity better than $99.9 \mathrm{wt} . \%$ under an argon atmosphere. The as-cast samples were wrapped by tantalum foil and annealed in a high-vacuum quartz tube at $1173 \mathrm{~K}$ for $96 \mathrm{~h}$, followed by quenching in ice water. It is noted that the effect of different heat treatments on the magnetic and magnetocaloric properties has been studied intensively in NiMn-based Heusler alloys [22-25]. It is revealed that the MCE can be largely improved by optimizing the heat treatment, e.g., an optimized annealing method can reproduce the excellent functional properties of Ni-Co-Mn-Al films in ribbons [25]. Here, we chose the same heat treatment from Reference [17], which also studied $\mathrm{Ni}_{50} \mathrm{Mn}_{34} \mathrm{Co}_{2} \mathrm{Sn}_{14}$ and presented giant MCE in this alloy. The final composition of the samples was determined by Energy Dispersive Spectrometry (EDS) using a JEOL-6060 Scanning Electron Microscope (SEM) from Akishima, Tokyo, Japan, and is shown in Table 1. It can be seen that the final composition is quite close to the nominal composition.

Table 1. Comparison of nominal composition and final composition. The deviation is shown in the bracket.

\begin{tabular}{cc}
\hline Nominal Composition & Final Composition \\
\hline $\mathrm{Ni}_{50} \mathrm{Mn}_{35} \mathrm{Co}_{2} \mathrm{Sn}_{13}$ & $\mathrm{Ni}_{49.9(8)} \mathrm{Mn}_{35.1(4)} \mathrm{Co}_{1.9(1)} \mathrm{Sn}_{13.1(4)}$ \\
$\mathrm{Ni}_{51} \mathrm{Mn}_{34} \mathrm{Co}_{2} \mathrm{Sn}_{13}$ & $\mathrm{Ni}_{50.9(11)} \mathrm{Mn}_{34.1(7)} \mathrm{Co}_{1.8(1)} \mathrm{Sn}_{13.3(9)}$ \\
$\mathrm{Ni}_{50} \mathrm{Mn}_{34} \mathrm{Co}_{3} \mathrm{Sn}_{13}$ & $\mathrm{Ni}_{50.1(9)} \mathrm{Mn}_{33.9(10)} \mathrm{Co}_{2.9(8)} \mathrm{Sn}_{13.2(7)}$ \\
$\mathrm{Ni}_{50} \mathrm{Mn}_{34} \mathrm{Co}_{2} \mathrm{Sn}_{14}$ & $\mathrm{Ni}_{50.0(10)} \mathrm{Mn}_{34.0(8)} \mathrm{Co}_{1.9(3)} \mathrm{Sn}_{14.1(7)}$ \\
\hline
\end{tabular}

The phase and crystal structure were investigated by using Rigaku D/max-2400 diffractometer with $\mathrm{Cu} K \alpha$ radiation from Tokyo, Japan. The differential scanning calorimetry (DSC) curves were measured using DSC 6220 with heating and cooling rates of $10 \mathrm{~K} / \mathrm{min}$. Magnetizations were measured as functions of temperature and the magnetic field using a cryogen-free cryocooler-based physical property measurement system (model VersaLab) from Quantum Design Inc., San Diego, CA, USA. 
In order to avoid the spurious magnetic entropy change $\left(\Delta S_{M}\right)$, induced by the residual effect generated in standard process, the magnetization isotherms curves were measured in a loop process, in which the sample is cooled down to the weak-magnetic martensite and then warmed up to the target temperature before starting each $M-H$ measurement. [26,27]. In this way, the phase transition is always crossed in the same sense. The $M-\mu_{0} H$ curves were corrected by taking into account the demagnetization effect, i.e., $H_{\text {int }}=H_{\text {ext }}-N_{d} M$.

\section{Results and Discussion}

Figure 1 shows the powder X-ray diffraction (XRD) patterns at an ambient temperature for all the alloys. The $\mathrm{Ni}_{50} \mathrm{Mn}_{35} \mathrm{Co}_{2} \mathrm{Sn}_{13}$ parent alloy crystallizes into the $10 \mathrm{M}$ modified orthorhombic martensitic structure at room temperature. In comparison, the XRD patterns reveal the matrix of austenitic phase with the Heusler $L 2_{1}$ cubic structure ( $F m \overline{3} m$ space group) for the other substituted alloys. This result indicates that the $T_{M}$ is above room temperature for the $\mathrm{Ni}_{50} \mathrm{Mn}_{35} \mathrm{Co}_{2} \mathrm{Sn}_{13}$ parent alloy while it is reduced to below room temperature by the substitution of $\mathrm{Mn}$. In addition, a small peak (denoted by " $\mathrm{r}^{\prime}$ ) is observed at the (2 20 ) Bragg peak of martensitic structure for $\mathrm{Ni}_{51} \mathrm{Mn}_{34} \mathrm{Co}_{2} \mathrm{Sn}_{13}$ and $\mathrm{Ni}_{50} \mathrm{Mn}_{34} \mathrm{Co}_{2} \mathrm{Sn}_{14}$, corresponding to the residual martensitic phase. Thus, it suggests that the $T_{M}$ of these two alloys is close to room temperature [28].

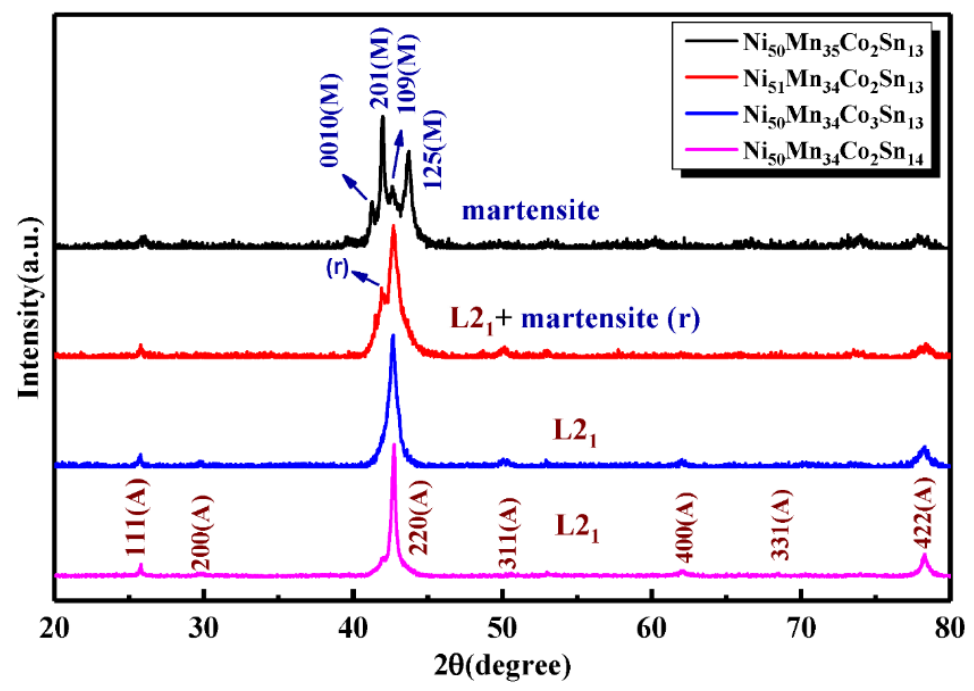

Figure 1. The powder X-ray diffraction (XRD) patterns at ambient temperature for Ni-Mn-Co-Sn alloys.

The DSC heat flow curves of Ni-Mn-Co-Sn alloys upon heating and cooling with a ramp rate of $10 \mathrm{~K} / \mathrm{min}$ are displayed in Figure 2a. Well-defined exothermic and endothermic peaks, with distinct thermal hysteresis, indicate the first-order martensitic and reverse martensitic transformations upon cooling and heating, respectively [29]. It is clearly seen that the $T_{M}$ of $\mathrm{Ni}_{50} \mathrm{Mn}_{35} \mathrm{Co}_{2} \mathrm{Sn}_{13}$ parent alloy is above room temperature, the $T_{M}$ of $\mathrm{Ni}_{51} \mathrm{Mn}_{34} \mathrm{Co}_{2} \mathrm{Sn}_{13}$ and $\mathrm{Ni}_{50} \mathrm{Mn}_{34} \mathrm{Co}_{2} \mathrm{Sn}_{14}$ is just below room temperature, and the $T_{M}$ of $\mathrm{Ni}_{50} \mathrm{Mn}_{34} \mathrm{Co}_{3} \mathrm{Sn}_{13}$ is much lower than room temperature, respectively. This result is consistent with our analysis based on the XRD measurements. Based on the DSC curves, the entropy change $(\Delta S)$ associated to the structural transformation was calculated by the following equation:

$$
\Delta S=\int_{T_{s}}^{T_{f}}\left[\left(\frac{d Q}{d t}\right)\left(\frac{d T}{d t}\right)^{-1} \frac{1}{T}\right] d T
$$

where $\frac{d Q}{d t}$ is the power of heat flow, $\frac{d T}{d t}$ is the heating or cooling rate, and $T_{S}$ and $T_{f}$ are the starting and finishing temperatures of the structural transformation, respectively. Table 2 lists the $\Delta S$ values at the structural transition for Ni-Mn-Co-Sn alloys. 
Table 2. The $\Delta S$ values at the structural transition obtained from DSC curves for Ni-Mn-Co-Sn alloys.

\begin{tabular}{cc}
\hline Alloys & $\Delta S(\mathbf{J} / \mathbf{k g ~ K})$ \\
\hline $\mathrm{Ni}_{50} \mathrm{Mn}_{35} \mathrm{Co}_{2} \mathrm{Sn}_{13}$ & 42.3 \\
$\mathrm{Ni}_{51} \mathrm{Mn}_{34} \mathrm{Co}_{2} \mathrm{Sn}_{13}$ & 28.2 \\
$\mathrm{Ni}_{50} \mathrm{Mn}_{34} \mathrm{Co}_{3} \mathrm{Sn}_{13}$ & 14.9 \\
$\mathrm{Ni}_{50} \mathrm{Mn}_{34} \mathrm{Co}_{2} \mathrm{Sn}_{14}$ & 31.6 \\
\hline
\end{tabular}

The Figure $2 \mathrm{~b}$ shows the martensitic transformation temperature $\left(T_{M}\right)$ and reverse martensitic transformation temperature $\left(T_{A}\right)$ as a function of different atomic substitution and valence electron concentration $e / a$. The number of valence electrons for $\mathrm{Ni}, \mathrm{Mn}, \mathrm{Co}$, and $\mathrm{Sn}$ atoms are $10\left(3 d^{8} 4 s^{2}\right)$, seven $\left(3 d^{5} 4 s^{2}\right)$, nine $\left(3 d^{7} 4 s^{2}\right)$, and four $\left(5 s^{2} 5 p^{2}\right)$, respectively. The $e / a$ value of Ni-Mn-Co-Sn alloys is calculated by the following equation [30]:

$$
e / a=\frac{10 \times \mathrm{Ni}_{a t . \%}+7 \times \mathrm{Mn}_{a t . \%}+9 \times \mathrm{Co}_{a t . \%}+4 \times \mathrm{Sn}_{a t . \%}}{\mathrm{Ni}_{a t . \%}+\mathrm{Mn}_{a t . \%}+\mathrm{Co}_{a t . \%}+\mathrm{Sn}_{a t . \%}}
$$

Generally, the $T_{M}$ of NiMn-based Heusler alloys is related to the $e / a$ and would increase with the increase of $e / a[11,29,31]$. However, it is found from Figure $2 \mathrm{~b}$ that the structural transformation temperature does not monotonously increase with the enhancement of $e / a$. This non-monotonical dependence of $T_{M}$ on $e / a$ has also been reported in other NiMn-based Heusler alloys [32-34]. In Heusler alloys $\mathrm{X}_{2} \mathrm{YZ}$, there are four Wyckoff-positions, namely A $(0,0,0), \mathrm{B}(0.25,0.25,0.25), \mathrm{C}(0.5,0.5,0.5)$, and $\mathrm{D}(0.75,0.75,0.75)$, respectively. Generally, the site preference of $X$ and $Y$ transition metal atoms is dependent upon the number of their valence electrons. The atom with more valence electrons prefers the $\mathrm{A}$ and $\mathrm{C}$ positions, while the atom with fewer valence electrons tends to occupy the $\mathrm{B}$ position, and the main group element $Z$ always enters into the $D$ site [35-37]. According to this rule, in the present case, Ni atoms with more valence electrons would occupy the $A$ and $C$ positions, while $\mathrm{Mn}$ atoms with the relatively fewest valence electrons would enter into the B position. Besides this, Sn, $\mathrm{Co}$, and excess $\mathrm{Mn}$ atoms occupy the $\mathrm{D}$ site. This speculation about the atomic occupation needs to be confirmed by further experiments. Based on the study of the correlation between the electronic structure and martensitic phase transition of Ni-Mn-Sn by hard X-ray photoelectron spectroscopy and ab initio calculation, the $d-d$ hybridization between $\mathrm{Ni} 3 d e_{g}$ states and the $3 d$ states of excess $\mathrm{Mn}$ atoms at $\mathrm{Sn}$ sites is believed to be the main driving force for the martensitic transformation $[38,39]$. Once the $d-d$ hybridization between $\mathrm{Ni}$ and $\mathrm{Mn}$ atoms is established, any change in the $\mathrm{Ni}$ or $\mathrm{Mn}$ content would tend to weaken the hybridization and reduce $T_{M}[38,39]$. Here, the substitution of Ni or Co for Mn atoms might lower the Mn content at Sn sites, thus reducing the $d-d$ hybridization between $\mathrm{Ni} 3 d e_{g}$ states and the $3 d$ states of excess Mn atoms at $\mathrm{Sn}$ sites-resulting in the decrease of $T_{M}$ in $\mathrm{Ni}_{51} \mathrm{Mn}_{34} \mathrm{Co}_{2} \mathrm{Sn}_{13}$ and $\mathrm{Ni}_{50} \mathrm{Mn}_{34} \mathrm{Co}_{3} \mathrm{Sn}_{13}$ alloys. On the other hand, the $p$ - $d$ covalent hybridization between the main group element $(\mathrm{Sn})$ and the transition metal element (Mn or $\mathrm{Ni}$ ) also plays an important role in stabilizing the parent phase [40,41], thus leading to the reduction of $T_{M}$ by increasing the content of $p$-group elements [9]. In $\mathrm{Ni}_{50} \mathrm{Mn}_{34} \mathrm{Co}_{2} \mathrm{Sn}_{14}$, the increase of Sn content would enhance the $p-d$ covalent hybridization and therefore reduce the $T_{M}$ by stabilizing the parent phase.

Figure 3a-d shows the temperature dependence of zero-field-cooling (ZFC) and field-cooling (FC) magnetization for all the alloys at $0.05 \mathrm{~T}$ and $3 \mathrm{~T}$, respectively. For the $\mathrm{Ni}_{50} \mathrm{Mn}_{35} \mathrm{Co}_{2} \mathrm{Sn}_{13}$ parent alloy with the highest $T_{M}$ (Figure 3a), the martensitic transformation nearly coincides with the paramagnetic (PM) to ferromagnetic (FM) magnetic transition of austenite, causing a small transition peak under $0.05 \mathrm{~T}$. With the application of a high field of $3 \mathrm{~T}$, the FM austenite can be induced by metamagnetic transition from both PM austenite and weak-magnetic martensite, which results in the decrease of $T_{M}$ and the increase of the magnetic transition temperature of austenite $\left(T_{C}^{A}\right)$, thus causing the more prominent transition peak [42]. Additionally, the $\mathrm{Ni}_{50} \mathrm{Mn}_{35} \mathrm{Co}_{2} \mathrm{Sn}_{13}$ parent alloy experiences a magnetic transition of martensite from a ferromagnetic to a weak-magnetic state at the $=190 \mathrm{~K}$. With the $T_{M}$ 
decreasing to below the $T_{C}^{A}$, the $\mathrm{Ni}_{51} \mathrm{Mn}_{34} \mathrm{Co}_{2} \mathrm{Sn}_{13}$ and $\mathrm{Ni}_{50} \mathrm{Mn}_{34} \mathrm{Co}_{2} \mathrm{Sn}_{14}$ undergo a magnetostructural martensitic transition from FM austenite to weak-magnetic martensite with distinct thermal hysteresis (Figure $3 \mathrm{~b}, \mathrm{~d}$ ). Moreover, a large $\Delta M$ of $35 \mathrm{Am}^{2} / \mathrm{kg}$ can be obtained in $\mathrm{Ni}_{50} \mathrm{Mn}_{34} \mathrm{Co}_{2} \mathrm{Sn}_{14}$ under $3 \mathrm{~T}$ through the magnetostructural transformation, which results in a large Zeeman energy difference between FM austenite and weak-magnetic martensite and implies a possibly high MCE according to the Clausius-Clapeyron relation $\Delta S=(\Delta M / \Delta T) \times \Delta \mu_{0} H$ [1]. For $\mathrm{Ni}_{50} \mathrm{Mn}_{34} \mathrm{Co}_{3} \mathrm{Sn}_{13}$ alloy, as shown in Figure $3 \mathrm{c}$, the $T_{M}$ further reduces to below the $T_{C}^{M}$, and thus a martensitic transformation from FM austenite to FM martensite is obtained.

The magnetization isotherms of Ni-Mn-Co-Sn alloys with increasing temperature upon field ascending and descending modes are presented in Figure $4 \mathrm{a}-\mathrm{d}$. The $M-\mu_{0} \mathrm{H}$ curves of $\mathrm{Ni}_{50} \mathrm{Mn}_{35} \mathrm{Co}_{2} \mathrm{Sn}_{13}$ parent alloy increases almost linearly with increasing magnetic field, corresponding to the typical characteristic of PM/weak-magnetic state (Figure 4a). Meanwhile, $M-\mu_{0} H$ curves around $T_{M}$ show a slight curvature with small magnetic hysteresis. This fact is attributed to the field-induced reverse martensitic transformation from weak-magnetic martensite to FM austenite, consistent with the result of thermomagnetic measurements in Figure 3a. Large magnetic hysteresis can be seen in the other substituted alloys, revealing the first-order martensitic transformation. As discussed above, the $\mathrm{Ni}_{50} \mathrm{Mn}_{34} \mathrm{Co}_{3} \mathrm{Sn}_{13}$ alloy experiences a martensitic transformation in an FM state, which can be confirmed by the strong curvatures of $M-\mu_{0} H$ curves around the transition temperature $T_{M}$ (Figure 4c). On the other hand, the $\mathrm{Ni}_{51} \mathrm{Mn}_{34} \mathrm{Co}_{2} \mathrm{Sn}_{13}$ and $\mathrm{Ni}_{50} \mathrm{Mn}_{34} \mathrm{Co}_{2} \mathrm{Sn}_{14}$ undergo a magnetostructural martensitic transition from FM austenite to weak-magnetic martensite. Therefore, a dramatic field-induced metamagnetic transition from weak-magnetic martensite to FM austenite with more distinct magnetic hysteresis is observed in Figure $4 \mathrm{~b}$,d. For example, the maximum hysteresis loss of $\mathrm{Ni}_{50} \mathrm{Mn}_{34} \mathrm{Co}_{2} \mathrm{Sn}_{14}$ reaches as high as $66 \mathrm{~J} / \mathrm{kg}$. This field-induced metamagnetic transition with remarkable hysteresis is attributed to the large Zeeman energy difference between the FM austenite and weak-magnetic martensite [43]. Meanwhile, it has to be pointed out that this large hysteresis loss during magnetization and demagnetization would lower the effective refrigerant capacity of the magnetic refrigerant, which is unfavorable for practical applications. Fortunately, the large hysteresis in Heusler alloys can be reduced effectively by fine-tuning the lattice parameters or using external bias stimuli such as hydrostatic pressure [5].

Based on the magnetization isotherms, the $\Delta S_{M}$ value can be calculated by using Maxwell relation [44]:

$$
\Delta S_{M}=\mu_{0} \int_{0}^{H}(\partial M / \partial T)_{H} d H
$$

The validity of the Maxwell relation for first-order magnetic transition has been disputed in the past years since a giant spurious spike may be obtained by using the Maxwell relation for the first-order magnetic transition $[45,46]$. However, recently Amaral et al. $[47,48]$ found that the breakdown of the Maxwell relation should not be interpreted as a consequence of the first-order magnetic transition, but a failure caused by not considering the non-equilibrium state of coexisting phases and the concomitant history dependence of the state. Furthermore, Caron et al. [26,49] pointed out that the spurious $\Delta S_{M}$ spike can be avoided by measuring the isothermal magnetization in a loop process, and so the Maxwell relation is still feasible for the first-order magnetic transition. Consequently, the Maxwell relation is applicable in the present work since the magnetization isotherms were measured in a loop process. Figure 5 a shows the temperature dependence of $\Delta S_{M}$ for Ni-Mn-Co-Sn alloys under different magnetic field changes of $1 \mathrm{~T}, 2 \mathrm{~T}$, and $3 \mathrm{~T}$, respectively. The $\mathrm{Ni}_{50} \mathrm{Mn}_{35} \mathrm{Co}_{2} \mathrm{Sn}_{13}$ parent alloy shows a small $\Delta S_{M}$ value of $2.0 \mathrm{~J} / \mathrm{kg} \mathrm{K}$ for a field change of $3 \mathrm{~T}$. On the other hand, large $\Delta S_{M}$ values can be obtained in the other substituted alloys, especially in the ones with magnetostructural martensitic transition. $\mathrm{Ni}_{50} \mathrm{Mn}_{34} \mathrm{Co}_{2} \mathrm{Sn}_{14}$ exhibits the highest $\Delta S_{M}$ value in this series of alloys, e.g., the maximum $\Delta S_{M}$ is $30.9 \mathrm{~J} / \mathrm{kg} \mathrm{K}$ for a field change of $3 \mathrm{~T}$. In comparison with the $\Delta S$ values at the structural transition listed in Table 2, it is seen that the $\Delta S_{M}(30.9 \mathrm{~J} / \mathrm{kg} \mathrm{K})$ under a field change of $3 \mathrm{~T}$ for $\mathrm{Ni}_{50} \mathrm{Mn}_{34} \mathrm{Co}_{2} \mathrm{Sn}_{14}$ is quite close the total entropy change $\Delta S$ of $31.6 \mathrm{~J} / \mathrm{kg} \mathrm{K}$ at the transition, suggesting that the $3 \mathrm{~T}$ is nearly the 
saturation magnetic field which leads to the completion of phase transformation from weak-magnetic martensite to FM austenite. Besides, the $\Delta S_{M}$ values for the rest of alloys are much lower than the $\Delta S$ values obtained from the calorimetric curves, indicating that the phase transformation in these alloys needs to be completed by a higher magnetic field.
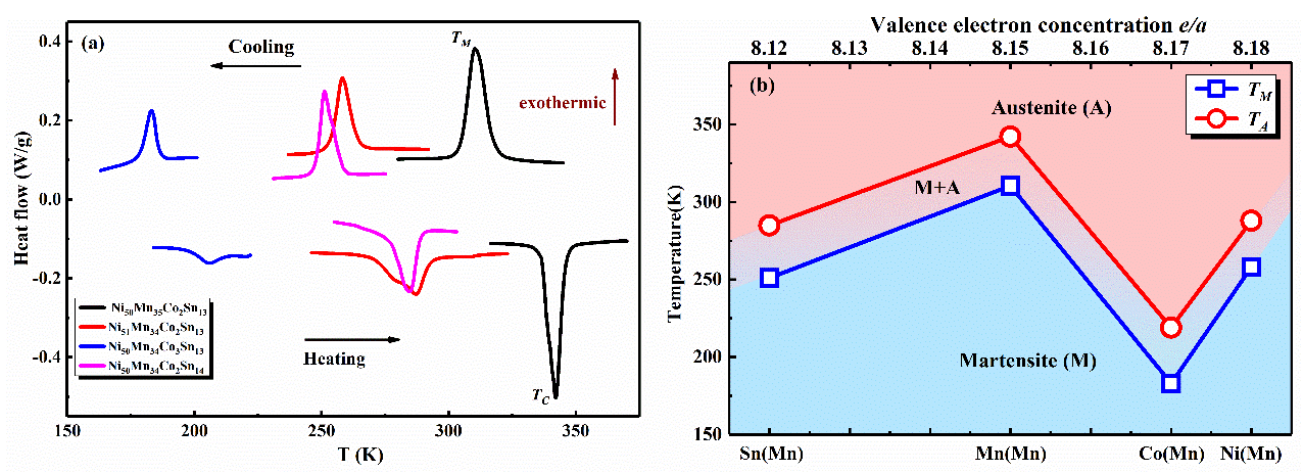

Figure 2. (a) The differential scanning calorimetry (DSC) heat flow curves of Ni-Mn-Co-Sn alloys upon heating and cooling with a ramp rate of $10 \mathrm{~K} / \mathrm{min}$. (b) The martensitic transformation temperature $\left(T_{M}\right)$ and reverse martensitic transformation temperature $\left(T_{A}\right)$ as a function of different atomic substitution and valence electron concentration $e / a$.
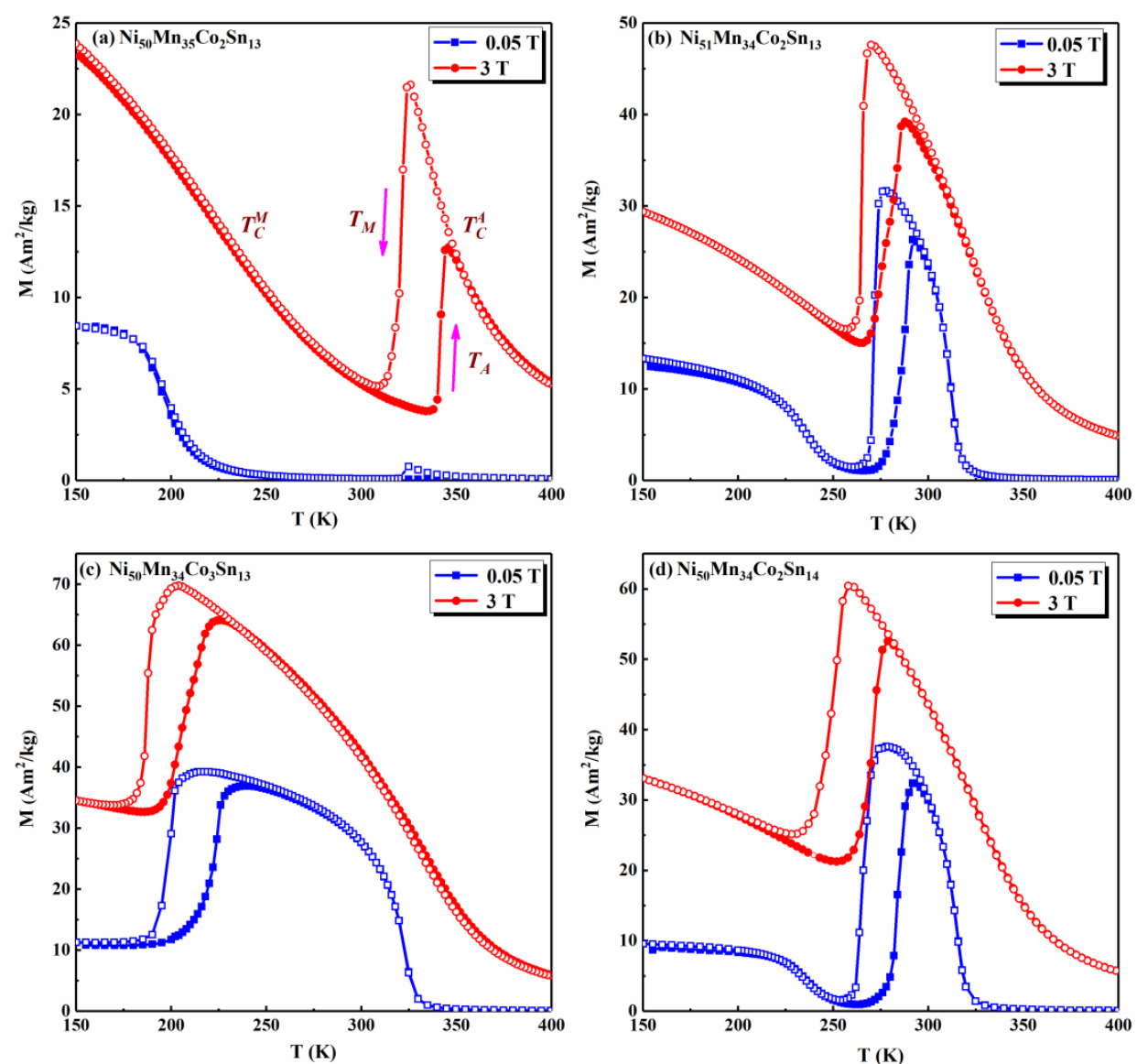

Figure 3. Temperature dependence of zero-field-cooling (ZFC) and field-cooling (FC) magnetization for Ni-Mn-Co-Sn alloys at $0.05 \mathrm{~T}$ and $3 \mathrm{~T}$, respectively. 

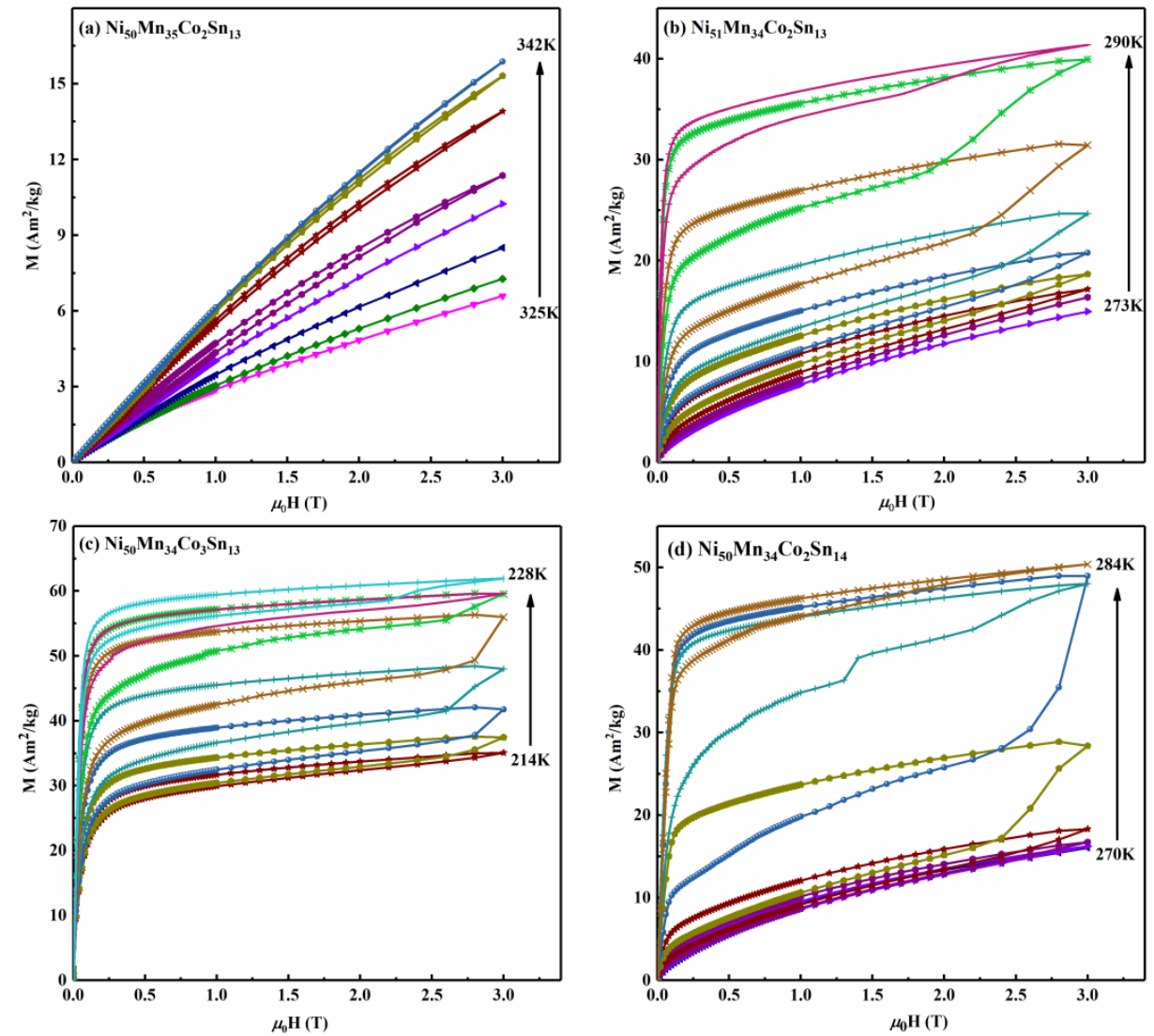

Figure 4. Magnetization isotherms of Ni-Mn-Co-Sn alloys with increasing temperatures upon field ascending and descending modes.
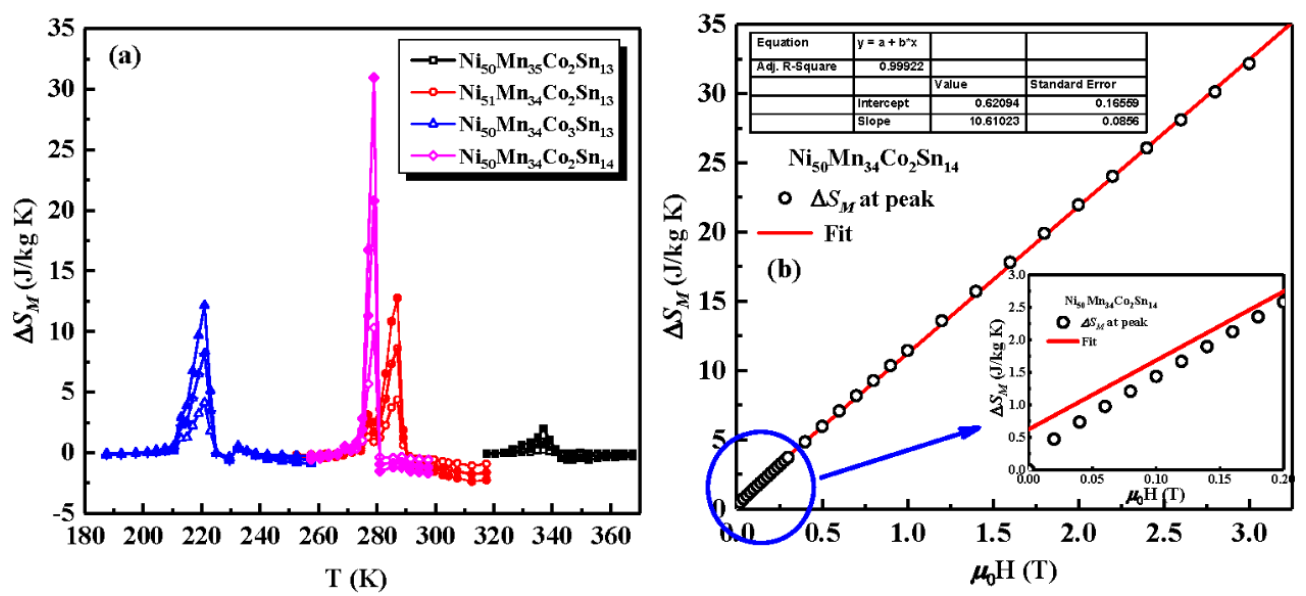

Figure 5. (a) Temperature dependence of $\Delta S_{M}$ for Ni-Mn-Co-Sn alloys under different magnetic field changes of $1 \mathrm{~T}, 2 \mathrm{~T}$, and $3 \mathrm{~T}$, respectively. (b) The maximum $\Delta S_{M}$ as a function of $\mu_{0} H$ and the fitting line to $\Delta S_{M-} \mu_{0} H$ curve for $\mathrm{Ni}_{50} \mathrm{Mn}_{34} \mathrm{Co}_{2} \mathrm{Sn}_{14}$ alloy. The inset shows the $\Delta S_{M-} \mu_{0} H$ curve and the fitting line at low fields.

In order to investigate the magnetic field dependence of $\Delta S_{M}$, the maximum $\Delta S_{M}$ as a function of $\mu_{0} \mathrm{H}$ for the $\mathrm{Ni}_{50} \mathrm{Mn}_{34} \mathrm{Co}_{2} \mathrm{Sn}_{14}$ alloy is plotted as an example in Figure $5 \mathrm{~b}$. It is noted that the $\Delta S_{M}$ follows a linear relationship with the variation of the magnetic field when $\mu_{0} H>0.2 \mathrm{~T}$ :

$$
\Delta S_{M}=\Delta S_{0}+\kappa \mu_{0} H
$$


where $\Delta S_{0}$ is the intercept value when the field is zero, and $\kappa$ is the slope factor which describes how strong the $\Delta S_{M}$ depends on $\mu_{0} H$. The adjusted R-squared factor is 0.99922 , indicating the excellent linear fitting. Similar linear relationships between $\Delta S_{M}$ and $\mu_{0} H$ have also been reported in other studies [50,51]. However, a slight deviation can be found in the low field range (inset of Figure $5 b$ ). The origin of this linear relationship and the deviation at low fields will be discussed in the following section.

Since the magnetization isotherms were measured at discrete temperature intervals, the Maxwell relation can be numerically approximated to [52]:

$$
\begin{aligned}
\Delta S_{M}\left(\frac{T_{1}+T_{2}}{2}, H\right) & =\frac{\mu_{0}}{T_{2}-T_{1}}\left[\int_{0}^{H} M\left(T_{2}, H\right) d H-\int_{0}^{H} M\left(T_{1}, H\right) d H\right] \\
& =\mu_{0} \sum_{i} \frac{M\left(T_{2}, H_{i}\right)-M\left(T_{1}, H_{i}\right)}{T_{2}-T_{1}} \Delta H_{i}
\end{aligned}
$$

where $M\left(T_{1}, H_{i}\right)$ and $M\left(T_{2}, H_{i}\right)$ are the magnetization values measured at temperatures $T_{1}$ and $T_{2}$ at a magnetic field $H_{i}$, respectively. Taking $278 \mathrm{~K}$ and $280 \mathrm{~K}$ as $T_{1}$ and $T_{2}$ for $\mathrm{Ni}_{50} \mathrm{Mn}_{34} \mathrm{Co}_{2} \mathrm{Sn}_{14}$ alloy, $\frac{M\left(T_{2}, H_{i}\right)-M\left(T_{1}, H_{i}\right)}{T_{2}-T_{1}}=\frac{\Delta M}{2}$, where $\Delta M$ is the difference between $M_{278} \mathrm{~K}$ and $M_{280 \mathrm{~K}}$ at $H_{i}$ upon field decreasing mode. Figure 6 shows the $\Delta M / 2$ between $278 \mathrm{~K}$ and $280 \mathrm{~K}$ as a function of the magnetic field for the $\mathrm{Ni}_{50} \mathrm{Mn}_{34} \mathrm{Co}_{2} \mathrm{Sn}_{14}$ alloy. According to Equation (5), the $\Delta S_{M}$ value at $279 \mathrm{~K}$ is the integral area under the $\Delta M / 2$ vs. $\mu_{0} H$ curve. It is found that the $\Delta M / 2$ increases sharply at low fields, which is due to the dramatic change of magnetization as shown in Figure $4 \mathrm{~d}$. Then, the $\Delta M / 2$ reaches a maximum value and starts to decrease. The decrease of $\Delta M / 2$ becomes slow after the break point $\Delta M_{\text {break }} / 2$. Thus, the $\Delta S_{M}$ can be divided into two parts by $\Delta M_{\text {break }} / 2$. The first part $\Delta S_{M 1}$ is the integral area below the critical field $\mu_{0} H_{\Delta M_{\text {break } / 2}}$, and it is a constant $\Delta S_{M 1 \max }$ when the field is higher than $\mu_{0} H_{\Delta M_{\text {break } / 2}}$.

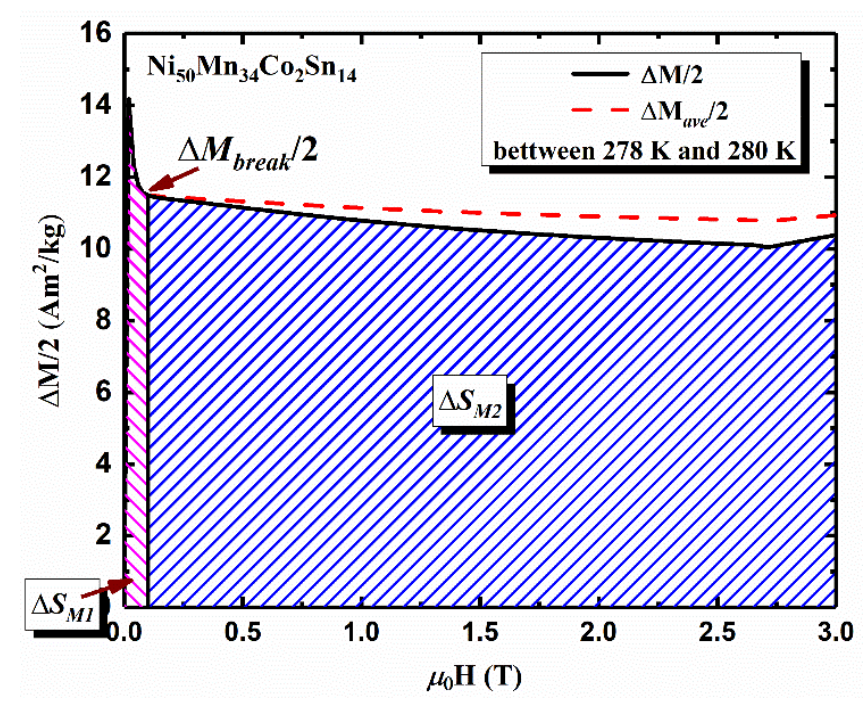

Figure 6. The $\Delta M / 2$ between $278 \mathrm{~K}$ and $280 \mathrm{~K}$ as a function of magnetic field $\mu_{0} H$ for $\mathrm{Ni}_{50} \mathrm{Mn}_{34} \mathrm{Co}_{2} \mathrm{Sn}_{14}$ alloy.

When the field is higher than the critical field $\mu_{0} H_{\Delta M_{\text {break } / 2}}$ of $\Delta M_{\text {break }} / 2, \Delta S_{M}=\Delta S_{M 1 \text { max }}+\Delta S_{M 2}$, where $\Delta S_{M 1 \max }$ is a constant as the integral area below $\Delta M_{\text {break }} / 2$ while $\Delta S_{M 2}$ is a variable as the integral area between the $\mu_{0} H_{\Delta M_{\text {break } / 2}}$, and the final field is $\mu_{0} H$. From Figure 6, the $\Delta S_{M 2}$ can be approximately considered to be a trapezoid, and so it could be estimated from

$$
\begin{aligned}
& \Delta S_{M 2}(T, H)=\frac{1}{2} \times\left(\Delta M_{\text {break }} / 2+\Delta M / 2\right) \times\left(\mu_{0} H-\mu_{0} H_{\Delta M_{\text {break } / 2}}\right) \\
& =\Delta M_{\text {ave }} / 2 \times\left(\mu_{0} H-\mu_{0} H_{\Delta M_{\text {break } / 2}}\right) \\
& =\left(-\Delta M_{\text {ave }} / 2 \times \mu_{0} H_{\Delta M_{\text {break } / 2}}\right)+\left(\Delta M_{\text {ave }} / 2 \times \mu_{0} H\right)
\end{aligned}
$$


where $\Delta M_{\text {ave }} / 2$ is the average value of $\left(\Delta M_{\text {break }} / 2+\Delta M / 2\right)$. Based on Equation (6), when field is higher than $\mu_{0} H_{\Delta M_{\text {break } / 2}}$, the total $\Delta S_{M}$ can be obtained from

$$
\begin{aligned}
\Delta S_{M} & =\Delta S_{M 1 \max }+\Delta S_{M 2} \\
& =\left(\Delta S_{M 1 \max }-\Delta M_{\text {ave }} / 2 \times \mu_{0} H_{\Delta M_{\text {break } / 2}}\right)+\left(\Delta M_{\text {ave }} / 2 \times \mu_{0} H\right)
\end{aligned}
$$

It is seen from Figure 6 that the $\Delta M_{\text {ave }} / 2$ is nearly constant when $\mu_{0} H>\mu_{0} H_{\Delta M_{\text {break } / 2}}$. Therefore, by comparing Equations (4) and (7), the first bracket of Equation (7) can be considered as $-\Delta S_{0}$ in Equation (4), and the second bracket of Equation (7) equates with the $\kappa \mu_{0} H$ in Equation (4). Consequently, the above numerical analysis and discussion reveals the origin of the linear relationship between $\Delta S_{M}$ and $\mu_{0} H$ at high fields in $\mathrm{Ni}_{50} \mathrm{Mn}_{34} \mathrm{Co}_{2} \mathrm{Sn}_{14}$ with first-order magnetostructural transition. On the other hand, this approximation does not hold when the field is lower than $\mu_{0} H_{\Delta M_{\text {break } / 2}}$, thus leading to the deviation of the linear relationship at low fields. In addition to the $\Delta S_{M}$ peak value, it is also interesting to find that other $\Delta S_{M}$ values at different temperatures also follow the linear relation at high fields by performing the same numerical analysis. It has to be pointed out that the $\Delta S_{M}$ would not further increase by increasing $\mu_{0} H$ when it reaches saturation. Therefore, this linear relationship between $\Delta S_{M}$ and $\mu_{0} H$ only exists below the saturation magnetic field.

\section{Conclusions}

In the present $\mathrm{Ni}-\mathrm{Mn}-\mathrm{Co}-\mathrm{Sn}$ system, the martensitic transformation temperature $T_{M}$ reduces largely in the substituted alloys. The decrease of $T_{M}$ is likely attributed to the reduction of $d$ - $d$ hybridization by substituting $\mathrm{Mn}$ with $\mathrm{Ni}$ or $\mathrm{Co}$ as well as the enhancement of $p$ - $d$ covalent hybridization by substituting $\mathrm{Mn}$ with $\mathrm{Sn}$. The $\mathrm{Ni}_{51} \mathrm{Mn}_{34} \mathrm{Co}_{2} \mathrm{Sn}_{13}$ and $\mathrm{Ni}_{50} \mathrm{Mn}_{34} \mathrm{Co}_{2} \mathrm{Sn}_{14}$ exhibit a magnetostructural martensitic transition from FM austenite to weak-magnetic martensite, which results in a giant MCE around room temperature. Moreover, a linear relationship between $\Delta S_{M}$ and $\mu_{0} \mathrm{H}$ is found in $\mathrm{Ni}_{50} \mathrm{Mn}_{34} \mathrm{Co}_{2} \mathrm{Sn}_{14}$, and the origin of this linear relationship is analyzed numerically based on the Maxwell relation.

Author Contributions: H.Z. (Hu Zhang) conceived and designed the experiments. C.X., Z.Q., D.H., and X.L. prepared the samples. C.X., Y.X., and H.Z. (HanNing Zhang) performed the measurements. H.Z. (Hu Zhang) and C.X. contributed to the data analysis and scientific interpretation. C.X. and H.Z. (Hu Zhang) drafted the article. K.L., Y.Z., and Y.L. made critical revisions to the article.

Funding: This work was funded by the National Natural Science Foundation of China [Grant No.: 51671022 and 51571018]; the National Key Research and Development Program of China [Grant No.: 2017YFB0702704]; the Beijing Natural Science Foundation [No. 2162022]; and the Scientific and Technological Innovation Team Program of Foshan [2015IT100044].

Conflicts of Interest: The authors declare no conflicts of interest.

\section{References}

1. Kainuma, P.; Imano, Y.; Ito, W.; Sutou, Y.; Morito, H.; Okamoto, S.; Kitakami, O.; Oikawa, K.; Fujita, A.; Kanomata, T.; et al. Magnetic-field-induced shape recovery by reverse phase transformation. Nature 2006, 439, 957-960. [CrossRef] [PubMed]

2. Koyama, K.; Okada, H.; Watanabe, K.; Kanomata, T.; Kainuma, R.; Ito, W.; Oikawa, K.; Ishida, K. Observation of large magnetoresistance of magnetic Heusler alloy $\mathrm{Ni}_{50} \mathrm{Mn}_{36} \mathrm{Sn}_{14}$ in high magnetic fields. Appl. Phys. Lett. 2006, 89, 182510. [CrossRef]

3. Yu, S.Y.; Ma, L.; Liu, G.D.; Liu, Z.H.; Chen, J.L.; Cao, Z.X.; Wu, G.H.; Zhang, B.; Zhang, X.X. Magnetic field-induced martensitic transformation and large magnetoresistance in NiCoMnSb alloys. Appl. Phys. Lett. 2007, 90, 242501. [CrossRef]

4. Wang, B.M.; Liu, Y.; Ren, P.; Xia, B.; Ruan, K.B.; Yi, J.B.; Ding, J.; Li, X.G.; Wang, L. Large exchange bias after zero-field cooling from an unmagnetized state. Phys. Rev. Lett. 2011, 106, 077203. [CrossRef] [PubMed]

5. Liu, J.; Gottschall, T.; Skokov, K.P.; Moore, J.D.; Gutfleisch, O. Giant magnetocaloric effect driven by structural transitions. Nat. Mater. 2012, 11, 620-626. [CrossRef] [PubMed] 
6. Krenke, T.; Duman, E.; Acet, M.; Wassermann, E.F.; Moya, X.; Mañosa, L.; Planes, A. Inverse magnetocaloric effect in ferromagnetic Ni-Mn-Sn alloys. Nat. Mater. 2005, 4, 450-454. [CrossRef] [PubMed]

7. Zhang, X.X.; Zhang, H.H.; Qian, M.F.; Geng, L. Enhanced magnetocaloric effect in Ni-Mn-Sn-Co alloys with two successive magnetostructural transformations. Sci. Rep. 2018, 8, 8235. [CrossRef] [PubMed]

8. Campbell, C.C.M. Hyperfine field systematics in Heusler alloys. J. Phys. F Met. Phys. 1975, 5, $1931-1945$. [CrossRef]

9. Sutou, Y.; Imano, Y.; Koeda, N.; Omori, T.; Kainuma, R.; Ishida, K.; Oikawa, K. Magnetic and martensitic transformations of $\mathrm{NiMnX}(\mathrm{X}=\mathrm{In}, \mathrm{Sn}, \mathrm{Sb})$ ferromagnetic shape memory alloys. Appl. Phys. Lett. 2004, 85, 4358-4360. [CrossRef]

10. Han, Z.D.; Wang, D.H.; Zhang, C.L.; Xuan, H.C.; Gu, B.X.; Du, Y.W. Low-field inverse magnetocaloric effect in $\mathrm{Ni}_{50-\mathrm{x}} \mathrm{Mn}_{39+\mathrm{x}} \mathrm{Sn}_{11}$ Heusler alloys. Appl. Phys. Lett. 2007, 90, 042507. [CrossRef]

11. Krenke, T.; Acet, M.; Wassermann, F.; Moya, X.; Mañosa, L.; Planes, A. Martensitic transitions and the nature of ferromagnetism in the austenitic and martensitic states of Ni-Mn-Sn alloys. Phys. Rev. B 2005, 72, 014412. [CrossRef]

12. Gao, B.; Hu, F.X.; Shen, J.; Wang, J.; Sun, J.R.; Shen, B.G. Field-induced structural transition and the related magnetic entropy change in $\mathrm{Ni}_{43} \mathrm{Mn}_{43} \mathrm{Co}_{3} \mathrm{Sn}_{11}$ alloy. J. Magn. Magn. Mater. 2009, 321, 2571-2574. [CrossRef]

13. Han, Z.D.; Wang, D.H.; Qian, B.; Feng, J.F.; Jiang, X.F.; Du, Y.W. Phase transitions, magnetocaloric effect and magnetoresistance in Ni-Co-Mn-Sn ferromagnetic shape memory alloy. Jpn. J. Appl. Phys. 2010, 49, 010211. [CrossRef]

14. Schleicher, B.; Klar, D.; Ollefs, K.; Diestel, A.; Walecki, D.; Weschke, E.; Schultz, L.; Nielsch, K.; Fähler, S.; Wende, H.; et al. Electronic structure and magnetism of epitaxial Ni-Mn-Ga(-Co) thin films with partial disorder: A view across the phase transition. J. Phys. D Appl. Phys. 2017, 50, 465005. [CrossRef]

15. Biswanath, D.; Körmann, F.; Hickel, T.; Neugebauer, J. Impact of Co and Fe doping on the martensitic transformation and the magnetic properties in Ni-Mn-based Heusler alloys. Phys. Status Solidi B 2018, 255, 1700455.

16. Liu, F.S.; Wang, Q.B.; Li, S.P.; Ao, W.Q.; Li, J.Q. Effect of Co substitution on the martensitic transformation and magnetocaloric properties of $\mathrm{Ni}_{50} \mathrm{Mn}_{35-\mathrm{x}} \mathrm{Co}_{x} \mathrm{Sn}_{15}$. Powder Diffr. 2013, 28, S22-S27. [CrossRef]

17. Yang, L.H.; Zhang, H.; Hu, F.X.; Sun, J.R.; Pan, L.Q.; Shen, B.G. Magnetocaloric effect and martensitic transition in $\mathrm{Ni}_{50} \mathrm{Mn}_{36-\mathrm{x}} \mathrm{Co}_{\mathrm{x}} \mathrm{Sn}_{14}$. J. Alloys Compd. 2014, 588, 46-48. [CrossRef]

18. Xuan, H.C.; Zheng, Y.X.; Ma, S.C.; Cao, Q.Q.; Wang, D.H.; Du, Y.W. The martensitic transformation, magnetocaloric effect, and magnetoresistance in high-Mn content $\mathrm{Mn}_{47+x} \mathrm{Ni}_{43-\mathrm{x}} \mathrm{Sn}_{10}$ ferromagnetic shape memory alloys. J. Appl. Phys. 2010, 108, 103920. [CrossRef]

19. Ray, M.K.; Bagani, K.; Banerjee, S. Effect of excess Ni on martensitic transition, exchange bias and inverse magnetocaloric effect in $\mathrm{Ni}_{2+\mathrm{x}} \mathrm{Mn}_{1.4-\mathrm{x}} \mathrm{Sn}_{0.6}$ alloy. J. Alloys Compd. 2014, 600, 55-59. [CrossRef]

20. Phan, T.L.; Zhang, P.; Dan, N.H.; Yen, N.H.; Thanh, P.T.; Thanh, T.D.; Phan, M.H.; Yu, S.C. Coexistence of conventional and inverse magnetocaloric effects and critical behaviors in $\mathrm{Ni}_{50} \mathrm{Mn}_{50-\mathrm{x}} \mathrm{Sn}_{\mathrm{x}}(\mathrm{x}=13$ and 14) alloy ribbons. Appl. Phys. Lett. 2012, 101, 212403. [CrossRef]

21. Zhang, P.; Phan, T.L.; Duc, N.H.; Dan, N.H.; Yu, S.C. Magnetocaloric and critical behavior of $\mathrm{Ni}_{0.5} \mathrm{Mn}_{0.5-\mathrm{x}} \mathrm{Sn}_{\mathrm{x}}$ Heusler alloys. IEEE Trans. Magn. 2012, 48, 3753-3756. [CrossRef]

22. Qian, M.F.; Zhang, X.X.; Wei, L.S.; Geng, L.; Peng, H.X. Effect of chemical ordering annealing on martensitic transformation and superelasticity in polycrystalline Ni-Mn-Ga microwires. J. Alloys Compd. 2015, 645, 335-343. [CrossRef]

23. Sánchez-Alarcos, V.; Pérez-Landazábal, J.I.; Recarte, V.; Rodríguez-Velamazán, J.A.; Chernenko, V.A. Effect of atomic order on the martensitic and magnetic transformations in Ni-Mn-Ga ferromagnetic shape memory alloys. J. Phys. Condens. Matter 2010, 22, 166001. [CrossRef] [PubMed]

24. Zhang, Y.; Zhang, L.L.; Zheng, Q.; Zheng, X.Q.; Li, M.; Du, J.; Yan, A.R. Enhanced magnetic refrigeration properties in Mn-rich Ni-Mn-Sn ribbons by optimal annealing. Sci. Rep. 2015, 5, 11010. [CrossRef] [PubMed]

25. Weise, B.; Dutta, B.; Teichert, N.; Hütten, A.; Hickel, T.; Waske, A. Role of disorder when upscaling magnetocaloric Ni-Co-Mn-Al Heusler alloys from thin films to ribbons. Sci. Rep. 2018, 8, 9147. [CrossRef] [PubMed]

26. Caron, L.; Ou, Z.Q.; Nguyen, T.T.; Cam Thanh, D.T.; Tegus, O.; Brück, E. On the determination of the magnetic entropy change in materials with first-order transitions. J. Magn. Magn. Mater. 2009, 321, 3559-3566. [CrossRef] 
27. Li, Y.W.; Zhang, H.; Tao, K.; Wang, Y.X.; Wu, M.L.; Long, Y. Giant magnetocaloric effect induced by reemergence of magnetostructural coupling in Si-doped $\mathrm{Mn}_{0.95}$ CoGe compounds. Mater. Des. 2017, 114, 410-415. [CrossRef]

28. Pathak, A.K.; Dubenko, I.; Standler, S.; Ali, N. The effect of partial substitution of In by Si on the phase transitions and respective magnetic entropy changes of $\mathrm{Ni}_{50} \mathrm{Mn}_{35} \mathrm{In}_{15}$ Heusler alloy. J. Phys. D Appl. Phys. 2008, 41, 202004. [CrossRef]

29. Qu, Y.H.; Cong, D.Y.; Sun, X.M.; Nie, Z.H.; Gui, W.Y.; Li, R.G.; Ren, Y.; Wang, Y.D. Giant and reversible room-temperature magnetocaloric effect in Ti-doped Ni-Co-Mn-Sn magnetic shape memory alloys. Acta Mater. 2017, 134, 236-248. [CrossRef]

30. Bao, B.; Long, Y.; Duan, J.F.; Shi, P.J.; Wu, G.H.; Ye, R.C.; Chang, Y.Q.; Zhang, J.; Rong, C.B. Phase transition processes and magnetocaloric effect in $\mathrm{Ni}_{2.15} \mathrm{Mn}_{0.85-\mathrm{x}} \mathrm{Co}_{\mathrm{x}} \mathrm{Ga}$ alloys. J. Appl. Phys. 2008, 103, $07 \mathrm{~B} 335$. [CrossRef]

31. Xuan, H.C.; Han, P.D.; Wang, D.H.; Du, Y.W. Magnetic and magnetocaloric properties in Cu-doped high Mn content $\mathrm{Mn}_{50} \mathrm{Ni}_{40-\mathrm{x}} \mathrm{Cu}_{\mathrm{x}} \mathrm{Sn}_{10}$ Heusler alloys. Intermetallics 2014, 54, 120-124. [CrossRef]

32. Gao, B.; Shen, J.; Hu, F.X.; Wang, J.; Sun, J.R.; Shen, B.G. Magnetic properties and magnetic entropy change in Heusler alloys $\mathrm{Ni}_{50} \mathrm{Mn}_{35-\mathrm{x}} \mathrm{Cu}_{\mathrm{x}} \mathrm{Sn}_{15}$. Appl. Phys. A 2009, 97, 443-447. [CrossRef]

33. Sahoo, R.; Nayak, A.K.; Suresh, K.G.; Nigam, A.K. Effect of Fe substitution on the magnetic, transport, thermal and magnetocaloric properties in $\mathrm{Ni}_{50} \mathrm{Mn}_{38-x} \mathrm{Fe}_{x} \mathrm{Sb}_{12}$ Heusler alloys. J. Appl. Phys. 2011, 109, 123904. [CrossRef]

34. Passamani, E.C.; Xavier, F.; Favre-Nicolin, E.; Larica, C.; Takeuchi, A.Y.; Castro, I.L.; Proveti, J.R. Magnetic properties of NiMn-based Heusler alloys influenced by Fe atoms replacing Mn. J. Appl. Phys. 2009, 105, 033919. [CrossRef]

35. Burch, T.J.; Litrenta, T. Hyperfine studies of site occupation in ternary systems. Phys. Rev. Lett. 1974, $33,421$. [CrossRef]

36. Luo, H.Z.; Yang, L.; Liu, B.H.; Meng, F.B.; Liu, E.K. Atomic disorder in Heusler alloy Cr ${ }_{2}$ CoGa. Phys. B 2015, 476, 110-113. [CrossRef]

37. Kandpal, H.C.; Fecher, G.H.; Felser, C. Calculated electronic and magnetic properties of the half-metallic, transition metal based Heusler compounds. J. Phys. D Appl. Phys. 2007, 40, 1507-1523. [CrossRef]

38. Ye, M.; Kimura, A.; Miura, Y.; Shirai, M.; Cui, Y.T.; Shimada, K.; Namatame, H.; Taniguchi, M.; Ueda, S.; Kobayashi, K.; et al. Role of electronic structure in the martensitic phase transition of $\mathrm{Ni}_{2} \mathrm{Mn}_{1+\mathrm{x}} \mathrm{Sn}_{1-\mathrm{x}}$ studied by hard-X-ray photoelectron spectroscopy and Ab Initio calculation. Phys. Rev. Lett. 2010, 104, 176401. [CrossRef] [PubMed]

39. Khan, M.; Jung, J.; Stoyko, S.S.; Mar, A.; Quetz, A.; Samanta, T.; Dubenko, I.; Ali, N.; Stadler, S.; Chow, K.H. The role of Ni-Mn hybridization on the martensitic phase transitions in Mn-rich Heusler alloys. Appl. Phys. Lett. 2012, 100, 172403. [CrossRef]

40. Gelatt, C.D., Jr.; Williams, A.R.; Moruzzi, V.L. Theory of bonding of transition metals to nontransition metals. Phys. Rev. B 1983, 27, 2005-2013. [CrossRef]

41. Wei, Z.Y.; Liu, E.K.; Chen, J.H.; Li, Y.; Liu, G.D.; Luo, H.Z.; Xi, X.K.; Zhang, H.W.; Wang, W.H.; Wu, G.H. Realization of multifunctional shape-memory ferromagnets in all-d-metal Heusler phases. Appl. Phys. Lett. 2015, 107, 022406. [CrossRef]

42. Arumugam, S.; Ghosh, S.; Ghosh, A.; Devarajan, U.; Kannan, M.; Govindaraj, L.; Mandal, K. Effect of hydrostatic pressure on the magnetic, exchange bias and magnetocaloric properties of $\mathrm{Ni}_{45.5} \mathrm{Co}_{2} \mathrm{Mn}_{37.5} \mathrm{Sn}_{15}$. J. Alloys Compd. 2017, 712, 714-719. [CrossRef]

43. Chen, L.; Hu, F.X.; Wang, J.; Bao, L.F.; Zheng, X.Q.; Pan, L.Q.; Yin, J.H.; Sun, J.R.; Shen, B.G. Magnetic entropy change and transport properties in $\mathrm{Ni}_{45} \mathrm{Co}_{5} \mathrm{Mn}_{36} \mathrm{In}_{13.4}$. J. Alloys Compd. 2013, 549, 170-174. [CrossRef]

44. Gschneidner, K.A., Jr.; Pecharsky, V.K.; Tsokol, A.O. Recent developments in magnetocaloric materials. Rep. Prog. Phys. 2005, 68, 1479-1539. [CrossRef]

45. Giguère, A.; Foldeaki, M.; Ravi Gopal, B.; Chahine, R.; Bose, T.K.; Frydman, A.; Barclay, J.A. Direct measurement of the "Giant" adiabatic temperature change in $\mathrm{Gd}_{5} \mathrm{Si}_{2} \mathrm{Ge}_{2}$. Phys. Rev. Lett. 1999, 83, 2262-2265. [CrossRef]

46. Sun, J.R.; Hu, F.X.; Shen, B.G. Comment on "Direct measurement of the 'Giant' adiabatic temperature change in $\mathrm{Gd}_{5} \mathrm{Si}_{2} \mathrm{Ge}_{2}$ ". Phys. Rev. Lett. 2000, 85, 4191. [CrossRef] [PubMed] 
47. Amaral, J.S.; Amaral, V.S. The effect of magnetic irreversibility on estimating the magnetocaloric effect from magnetization measurements. Appl. Phys. Lett. 2009, 94, 042506. [CrossRef]

48. Amaral, J.S.; Amaral, V.S. On estimating the magnetocaloric effect from magnetization measurements. J. Magn. Magn. Mater. 2010, 322, 1552-1557. [CrossRef]

49. Smith, A.; Bahl, C.R.H.; Bjørk, R.; Engelbrecht, K.; Nielsen, K.K.; Pryds, N. Materials challenges for high performance magnetocaloric refrigeration devices. Adv. Energy Mater. 2010, 2, 1288-1318. [CrossRef]

50. Krenke, T.; Duman, E.; Acet, M.; Moya, X.; Mañosa, L.; Planes, A. Effect of Co and Fe on the inverse magnetocaloric properties of Ni-Mn-Sn. J. Appl. Phys. 2007, 102, 033903. [CrossRef]

51. Wei, Z.Y.; Liu, E.K.; Li, Y.; Xu, G.Z.; Zhang, X.M.; Liu, G.D.; Xi, X.K.; Zhang, H.W.; Wang, W.H.; Wu, G.H.; et al. Unprecedentedly wide Curie-temperature windows as phase-transition design platform for tunable magneto-multifunctional materials. Adv. Electron. Mater. 2015, 1. [CrossRef]

52. Pecharsky, V.K.; Gschneidner, K.A., Jr. Magnetocaloric effect from indirect measurements: Magnetization and heat capacity. J. Appl. Phys. 1999, 86, 565-575. [CrossRef]

(C) 2018 by the authors. Licensee MDPI, Basel, Switzerland. This article is an open access article distributed under the terms and conditions of the Creative Commons Attribution (CC BY) license (http:/ / creativecommons.org/licenses/by/4.0/). 